\title{
Teaching Writing through Reading Integration
}

\author{
Luu Trong Tuan \\ Ho Chi Minh City University of Finance-Marketing, Vietnam \\ Email: luutrongtuan@vnn.vn
}

\begin{abstract}
There has not been a consensus among the researchers though the question whether writing teachers use reading activities in pre-writing phase in their writing class has been long posed. This paper is an endeavour to examine the extent to which reading integration approach is beneficial to EFL learners' writing performance.
\end{abstract}

Index Terms - teaching writing, reading, EFL

\section{INTRODUCTION}

Hedge (1998) declared that writing skill was often relegated to the status of "homework" due to limitation of time and syllabus outcomes, thus having no effects on the possibility of the teacher guidance. As structuralists and audio linguists emphasized oral forms of communication and reading, according to Tribble (1996), writing was considered as a tool for the practice and reinforcement of specific grammatical and lexical patterns; accuracy being all important whereas content and self expression given little if any priority. The students who were expected to produce an error-free coherent text without giving any prior thought to the meaning of the finished product encountered numerous seemingly insurmountable obstacles as Trible (1996) stated that they were basically "writing to learn" and not "learning to write" as instructed by this traditional product-oriented approach.

This view, nonetheless, has changed considerably along with the development of the communicative language teaching since 1980s since there was a widespread recognition that writing was a process which involves several steps in creating a piece of work. According to Silva (1990, p. 15), this tendency, namely the process-oriented approach, needed step-by-step developments, one of which was the integration of reading and writing.

As far as we have concerned, reading and writing have a mutual effect. Reading builds the knowledge of diverse kinds to write on or to employ in writing; writing reinforces knowledge in a way that builds schemata to read with. Reading and writing interact with each other, possibly making use of the same cognitive structures to create a text world (Kucer, 1985). Thus, an integrated-skill classroom is an ideal environment to apply Steve Peha's "Read like a writer" approach as an integration and reciprocal interaction of reading and writing.

This research is an endeavour to investigate the extent to which Steve Peha's read-like-a-writer approach is beneficial to EFL learners and thereby to attain a better way to teach integrated reading and writing courses. Questions guiding this research encompass:

1. What are the possible problems facing students in writing essays?

2. Can the application of Steve Peha's read-like-a-writer approach related to critical and analytic reading activities in pre-writing stage have effects on the students' writing competence?

\section{LITERATURE REVIEW}

\section{A. What is Writing?}

Writing is a process, not a "product which has been far being new. Also, writing is a complex process of exploring one's thought, discovering ideas and generating meaning (Flower and Hayes, 1980). In this way, the writing process is a sharp tool to discover meaning, to perfect a piece of writing both in thoughts and in grammatical accuracy and to bring intelligence to the writing. Therefore, Byrne (1988) declares writing is a process of encoding (putting your message into words) carried out with the reader's expectations; or, as confirmed by Nunan (1999, p. 273), "a complex, cognitive process that required sustained intellectual effort over a considerable period of time".

\section{B. Influence of Reading on Writing}

The influence of reading on writing has been expressed through the concept in which reading is trying to discover what a piece of written text means by understanding the words a writer is using. When reading, "we don't just wait for the meaning to come to us, we go for it-aggressively. We look deeply into the text hunting in certain specific ways searching for clues as to what the writer is trying to say." (Peha, 2003:3)

Taking into consideration the effects of reading on writing, there are a number of studies that fail to show an apparent correlation between reading and writing ability with the intention of proving that writers must also be readers. For instance, Battle (1986) concluded that freshmen did not appear to absorb reading skills as a function of learning to write. 
Or, several compositions themselves have not been without ambivalence toward the importance of reading in improving student writing (Morrow, 1997).

Nonetheless, reading can advance learners' ability to write since reading can aid the learners' process of writing as affirmed by Brown (1987, p. 331), "by reading and studying a variety of relevant types of text, students can gain important insights both about how they should write and about subject matter that may become the topic of their writing." In other words, reading can provide models for writing. Murcia and Olshtain (2000, p. 158) state that:

Many writing course and certainly most autodidactic strategies in writing involve using well-written passages form literature, or passage written by others, as models for one's own writing. Thus, many writing classes begin with reading texts, analyze them, looking at them as models for writing or using them as a piece of communication to response to.

For these reasons, reading playing a decisive role in the development of writing ability for reading appears to be an essential pre-condition to produce good writers.

\section{The Read-like-a-writer Approach}

Although the correlation between reading and writing has been adopted by most researchers, it is infrequent to make out this association practiced in second language writing classrooms. It can be probably explained that research has not provided a straightforward performance of this relationship. The researcher, after studying the researches related to reading-writing connection, found that in order to exploit reading in writing classes, teachers have to (1) let students know how their writing pieces are evaluated and (2) guide them to read like writer to acquire writers' ideas and crafts so that they can improve their writing proficiency and get higher writing scores. Based on this standpoint, some scholars claim the writer as a reader and the reader as a writer (Smith, 1983). Smith (1983) agrees reading like a writer allows one to actually become a writer. When reading like a writer, other than making meaning of the text, the reader takes in and learns from the author's style, use of conventions and the like. When reading like a writer, the reader uses the author's text as a model for the texts that he or she reader will ultimately write.

In order to make the read-like-a-writer approach be more apparently understood, Spandel (1996) shares that if the teacher truly want their students to read in order to write, they must make certain that our reading instruction promotes them to focus on those fundamentals of a written piece that make writing valuable. Reading trait-based writing, a confirmed method for helping students grow to be stronger writers, is relied heavily upon this thought: identifying the qualities that skilled, experienced readers believe make writing successful. It is quite accurate to say one of the widelyused reading-based programs is the six-trait writing because it exploits the use of reading texts to exemplify how writing works. The six traits, which most readers search for in any piece of writing are ideas (clarity, thought, support, and detail), organization (internal structure), voice, word choice, sentence fluency (rhythm and flow), and conventions (mechanical correctness as well as the use of textual conventions such as bold type or graphics). The entire six-trait writing approach is based upon the philosophy of placing what can be gained as reader into the writer's work. Each of the six traits is interrelated into the Reader's Handbook - only from a slightly different perspective. According to the handbook, students approach text samples as readers. Hopefully, they will not only enhance their reading skills but also apply what they know as writers. Smith (1983, pp. 52-53) points out:

To read like a writer we engage with the author in what the author is writing. We anticipate what the writer will say, so that the author is in effect writing on our behalf, not showing how something is done but doing it with us. This is identical spoken language situation where adults help children say what they want to say or would like and expect to be able to say. The author becomes an unwriting collaborator. Everything the learner would want to spell the author spells. Every thing the learner would want to punctuate the authors punctuates. Every nuance of expression, every relevant syntactic device, and every turn of phrase, the author and learner write together. Bit by bit, on thing at a time, but enormous number of things over the passage of time, the learner learns through reading like a writer to write like a writer.

\section{METHODOLOGY}

\section{A. Participants}

\section{Student sample}

The student sample comprised two classes of sixty-three full-time EFL students at Ho Chi Minh City University of Finance-Marketing. Class 09B (30 students) was randomly selected as control group and Class 09E (33 students) as experimental group. However, when the questionnaires were delivered at the end of the course, the collected data were 58 ( 28 from Class 09B and 30 from Class 09E), since there were absentees on the day the questionnaires were handed out. The majority of the students were 21 or 22 years old. The predominant gender of the surveyed group (93.1\%) was female. Almost all of the students $(98.3 \%)$ have learned English since they were in junior secondary school.

\section{Teacher sample}

A group of eight teachers including two males (25\%) and six females (75\%) were given a questionnaire similar to the students'. Undoubtedly, the responses from Teachers' questionnaire are indispensable because it is necessary to understand students' writing problems from another point of view: the instructors. $62.5 \%$ of them had eight or more 
years of teaching experience. In terms of degree, three had a MA, one was studying for an MA and the remaining four had a BA.

\section{B. Instruments}

\section{Pretest and posttest}

Pretest

The pretest was administered in the second week, after the students were taught carefully about essay. The tests were monitored and controlled carefully. The students of two groups were asked to write with the same topic in ninety minutes in the class. The purpose was that the result of the pretest would show whether the two groups' English level was the same because if the level of students would be a great variance, it would cause difficulty in administering the experiment and in the interpretation of the result of the study.

Posttest

As to the posttest, the students were asked to write an argumentative essay in ninety minutes after nine weeks of learning the academic essay writing for the purpose of observing whether the application of Steve Peha's read-like-awriter approach can help to improve English writing performance and to what extent the use of this application is helpful in their writing. Also, the posttest would be administered in the classroom to ensure the same physical conditions for the students, because the physical conditions are not exactly the same, expected results might not be reached.

Scoring

63 writing papers of each topic, i.e. 126 essays in all, were computerized to guarantee that the students' handwriting did not affect the way the teachers evaluated the students' essays before being distributed to each of the two experienced teachers (coded as T1 and T2). The essays were numbered from 1 to 126 so that the teachers might not get the impression that they were evaluating the essays written by the students of two different groups. Each of the two teachers was then requested to evaluate 126 essays, employing the same essay writing rubric. The essay writing rubric were basically designed based on the criteria of a well-formed essay from the perspective of Steve Peha's read-like-awriter. However, there would be 6 elements from Steve Peha's approach: organization, ideas, voice, word choice, sentence fluency and convention, the voice criterion was omitted. It can be explained by two reasons: first, it was extremely hard for foreign language learners to recognize the voice of the author as voice reveals the authors' personality and second, in order to avoid the issue of distraction when too many criteria were included in the writing rubric, the study only considered five criteria which are commonly mentioned in writing rubric 1) organization, 2) ideas, 3 ) word choice, 4) sentence fluency and 5) convention. After that, the teachers had an appointment to reach unanimous agreement on the students' scores. The evaluation process lasted more than four months.

Survey questionnaires

Student questionnaire

Student questionnaire was contrived to elicit information on the respondents' English learning background, attitudes towards essay writing and suggestions to improve the teaching and learning of essay writing performance. There were 10 questions divided into two parts in student questionnaire. The first three questions were meant to gain better understanding of the respondents' English learning background including gender, age, the time they began to learn English. The next seven questions were in the form of ended and open-ended questions: the former requested the students to tick their selected answers or put their choice in a priority order while the latter provided appropriate space for the subjects to write in. Each section of student questionnaire was designed to serve a certain purpose:

- The first three questions were designed to elicit the students' perception of the importance of writing skill and their habit of writing practice. The purpose is to identify how frequently the students practice their writing: never practice, write as required; and to assert whether essay writing is an indeed difficult task.

- The next four questions which were designed based on the criteria of a well-formed essay from the perspective of Steve Peha's read-like-a-writer approach such as rubric 1) organization, 2) ideas, 3) word choice, 4) sentence fluency and 5) convention

\section{Teacher questionnaire}

There were 12 questions divided into two parts in Teachers' questionnaire. The first part, which included five questions for the subjects' gender, age, educational background, years of teaching, and whether they have taught writing, helped the researcher eliminate the answers given by those who did not meet the requirements of the study. The second part consisted of seven questions which were the same as the second part's seven questions in student questionnaire.

\section{Experimental Teaching}

In the control group, the syllabus was designed to cover all the requirements of the course, that is, it would mention all the types of academic essays throughout the main course book "Refining Composition Skills: Rhetoric and Grammar for ESL students" by Smalley and Ruetten (1986) with the reading comprehension questions added to help the students understanding the texts. 
In the experimental group, the syllabus was designed to ensure totally that (1) the requirements of the course was sufficiently met, like what was done in the control group and (2) the part of applying the critical and analytic questions designed based on the perspective of writer so as to be considered as read-like-a-writer way.

Therefore, Steve Peha' read-like-a-writer approach was applied in the teaching of experimental group. Accordingly, the criteria of the approach such as organization, ideas, word choice, voice, sentence fluency and convention were taught in the form of questions for writing exploration.

During nine weeks of learning, both groups were fundamentally taught the same general knowledge about essay: introduction to the essay, six basic academic types of essay. It was worth to note that the first chapter was well taken care of because this was the orientation chapter in which students were taught about what to do and how to do it throughout the course. Another thing to note was that the two classes were taught exactly the same in the first week to ensure the validity of the pretest they would do the week later. And from the third week, the two classes will study differently with the application of Steve Peha's read-like-a-writer approach for the experimental group.

\section{RESULTS AND DisCUSSIONS}

\section{A. Writing Test Results}

\section{Criteria based analysis of writing tests}

TABLE 1.

CRITERIA BASED ANALYSIS OF PRETEST AND POSTTEST

\begin{tabular}{|c|c|c|c|c|c|c|}
\hline \multirow[t]{2}{*}{ No. } & \multirow[t]{2}{*}{ Criteria } & & \multicolumn{2}{|c|}{$\begin{array}{l}\text { 09B - control group } \\
\text { (30 students) }\end{array}$} & \multicolumn{2}{|c|}{$\begin{array}{l}\text { 09E - experimental group } \\
\text { (33 students) }\end{array}$} \\
\hline & & & Pretest & Posttest & Pretest & Posttest \\
\hline \multirow{2}{*}{1} & \multirow{2}{*}{ Organization } & Cannot state the problem & $10(33.3 \%)$ & $3(10 \%)$ & $12(36 \%)$ & $4(12 \%)$ \\
\hline & & Not have a thesis statement & $11(36.3 \%)$ & $3(10 \%)$ & $12(36 \%)$ & $3(9 \%)$ \\
\hline \multirow{2}{*}{2} & \multirow{2}{*}{ Ideas } & Not have logical ideas & $11(36.3 \%)$ & $5(16.5 \%)$ & $14(42 \%)$ & $1(3 \%)$ \\
\hline & & Cannot narrow topic & $10(33.3 \%)$ & $5(16.5 \%)$ & $13(39 \%)$ & $2(6 \%)$ \\
\hline \multirow[t]{2}{*}{3} & \multirow[t]{2}{*}{ Word choice } & $\begin{array}{l}\text { Use basic and known } \\
\text { vocabulary }\end{array}$ & $14(46.2 \%)$ & $4(13.2 \%)$ & $16(48 \%)$ & $5(15 \%)$ \\
\hline & & Translation form Vietnamese & $22(76.6 \%)$ & $10(33.3 \%)$ & $26(78 \%)$ & $12(36 \%)$ \\
\hline \multirow{2}{*}{4} & \multirow{2}{*}{$\begin{array}{l}\text { Sentence } \\
\text { fluency }\end{array}$} & Unnatural linking & $12(39.6 \%)$ & $8(26.4 \%)$ & $15(45 \%)$ & $10(30 \%)$ \\
\hline & & Limited variety of sentences & $20(66 \%)$ & $12(39.6 \%)$ & $22(66 \%)$ & $10(30 \%)$ \\
\hline \multirow[b]{2}{*}{5} & \multirow[b]{2}{*}{ Convention } & Error in grammar & $16(52.8 \%)$ & $9(29.7 \%)$ & $19(57 \%)$ & $11(33 \%)$ \\
\hline & & $\begin{array}{l}\text { Misspelling and } \\
\text { inappropriate punctuation }\end{array}$ & $13(42.9 \%)$ & $6(19.8 \%)$ & $16(48 \%)$ & $6(18 \%)$ \\
\hline
\end{tabular}

\section{Analysis of organization}

In the pretest, Class 09B has 10 students (33.3\%) which cannot state the problems and 11 students (36.3\%) which cannot write the thesis statement of the assigned topic. Meanwhile, among 12 students (36\%) of Class 09E, 10 students $(33.3 \%)$ cannot state the problems and 11 students $(36.3 \%)$ cannot write the thesis statement of the assigned topic. It seems 09B-ers are slightly better than 09E-ers in the pretest.

In the posttest, however, in spite of the number of students of 09B and 09E respectively $3(10 \%)$ and $4(12 \%)$ cannot state the problem; there are the same with 3 students in each class that cannot write the thesis statements. It means that the students in 09E can get marginal improvement in organization of the writing essay rather than students of 09B.

Analysis of ideas

In the pretest, there are $36.3 \%$ (11 students) cannot have logical ideas for their writing and $33.3 \%$ (10 students) cannot narrow down the given topic in 09B. And 09E has 42\% (14 students) cannot have logical ideas for their writing and 39\% (13 students) cannot narrow down the given topic. It shows that 09B-ers are also a little bit better than 09E-ers in identifying the ideas for the essay writing.

Nevertheless, 09E can create a dramatically change in the posttest: there are only one (1) student that did not have logical ideas and 2 students who cannot narrow the topic; whereas there are $5(16,5 \%)$ students cannot have logical ideas for their writing and $5(16,5 \%)$ students cannot narrow down the given topic in Class 09B.

It is possible to say that after nine weeks studying the two different syllabuses which were designed for these two groups: 09B-control group and 09E-experimental group, the 09E-ers can receive more input from the application of Steve Peha' s read-like-a-write approach in learning writing than 09B-ers that just studied without the association of the read-like-a-writer approach.

Analysis of word choice

The ability of 09E-ers of choosing appropriate words for their writing in the pretest also indicates that they were not as good as 09B-ers. 48\% (16 students) of 04B only use the basis simple vocabulary which they already knew before and $78 \%$ (26 students) translate their writing exactly from Vietnamese and they really did not care about which word can be used in such situations. While 09B also has the same phenomenon but with a smaller number; only 14 students (46,2\%) use the basis simple vocabulary and 22 students $(72,6 \%)$ translate their writing from Vietnamese. 
In the posttest, both the two classes have some improvements in word choice for essay writing. It reveals the theory of "reading having influence on writing" can work effectively in the integrated reading-writing classroom when the percentages of students of the two classes of the study are nearly the same.

Analysis of sentence fluency

It is similar to the analysis of Word choice, the number of the students of both classes have mistakes in this part of pretest is rather high. It is up to 12 09B-ers (39.6\%) cannot link the sentences naturally because they usually used some common conjunctions for instance "and, but", etc.; and 20 09B-ers are short of the ability to use varied sentence structures; instead they used basis, simple and short sentences that make their writing unsmooth and incoherent. So do 09E-ers. There are 15 students (45\%) lacking the natural linking of the writing and 22 students (66\%) use simple and short sentences in order to avoid the errors in grammar and structures.

Again in the posttest, the performances of 09E-ers can ensure the effective implement of Steve Peha' approach because they can improve more than 09B-ers. There are only 10 students (30\%) who cannot know how to link their sentences naturally. That means $15 \%(45 \%$ - 30\%) students who had such mistakes decreased. Class 09B still had 8 students who linked their sentences unnaturally with the decreasing of $13.2 \%(39.6 \%-26.4 \%)$ in comparison with $15 \%$ of Class 09E.

Especially, the students who can merely use some limited variety of sentences of Class 09E considerably decrease from $66 \%$ (22 students) to 30\% (10 students). Meanwhile, Class 09B has 12 students (39.6\%) who had such mistakes, decreasing $26.4 \%(66 \%-39.6 \%)$ in comparison with $36 \%(66 \%-30 \%)$ of Class 09E.

Analysis of convention

In both two classes, the numbers of the students who have errors in grammar are high in the pretest: 16 students $(52,8 \%)$ in Class 09B and $19(57 \%)$ in Class 09E. Also with the errors in using inappropriate punctuation and misspelling, 09B-ers occupy 42.9\% (13 students) and 09E-ers are 16 students (48\%).

However, in the posttest, both of them can get progress: there are 9 09B-ers $(29.7 \%)$ have errors in grammar and 6 09B-ers $(19,8 \%)$ use inappropriate punctuation and misspelling. While there are 11 09E-ers (33\%) have errors in grammar and 6 09E-ers (18\%) use inappropriate punctuation and misspelling.

In a nutshell, this analysis shows that in the pretest, the students seemed to struggle with their performances. 09B-ers resorted to translating the ideas that appeared suddenly in their minds from Vietnamese structures and 09E-ers left many sentences unfinished due to the lack of vocabulary and grammar knowledge or the inability in using word choice for appropriate words, or simply the unfamiliarity with writing an essay following a strictly obliged English style format or organization. Moreover, in terms of sentence fluency, very few students from both classes could compose fluent sentences with correct punctuation and spelling. This was understandable since these aspects were not taught or corrected carefully in the previous writing course.

Also, from this analysis, the difference between 09B-ers and 09E-ers was that 09B-ers were more focused on expressing all the current ideas in their minds in English. Although this resulted in falling back on L1 structures and lexicon to express ideas in L2, this attempt suggested that generally 09B-ers were more motivated to elaborate on their writing performance. And as they tended to write much, they tended to show more and more grammar mistakes on the long run.

09E-ers, on the other hand, seemed to be more "passive" in their attempt to express their ideas in English. This resulted in the fact that they could not elaborate much on their writing performance. This advantage was that they did not have to fall back on L1 to express their ideas and they seemed to take a good control of the grammar. But their writing performances were poor in English.

By and large, in terms of language use, it can be said that 09B-ers were little better than 09E-ers at first. However, after the implementation of the read-like-a-writer-enhanced syllabus, the writing performances of 09E-ers were much better while the writing performance of 09B-ers in general did not improve much.

\section{Analysis of writing test scores}

The pretest scores reveal that 09E-ers are generally not as good as 09B-ers. In fact, the gap is slightly big between the two classes. While $42.4 \%$ of 09E-ers scored from 4 to below 5, only $13.3 \%$ of 09B-ers did. And while the percentage of 09E-ers who scored from 5 to below 6 was little higher than that of 09B-ers (42.4\% compared to 40\%), more 09B-ers got into the 6-to-below-7 range (36.7\%, as compared to $9.1 \%$ that is 4 times difference). The majority of 09E-ers scored from 4 to below 6, while the majority of 09B-ers scored from 5 to below 7 . The percentage of exceptional students who scored above 7 in the pretest in both classes were basically the same (with that of Class 09B was a bit higher, 6.7\% compared to $6.1 \%$ in Class 09E).

The posttest scores show a significant change in the experimental class. While the percentage of students who scored from 4 to below 5 in 09B remains the same, 27.2\% (42.4\% - 15.2\%) less of 09E-ers' scores belonged to this range. Moreover, $18.2 \%(60.6 \%-42.4 \%)$ more of 09E-ers scored from 5 to below 6 and the percentage of 09E-ers who scored from 6 to below 7 doubled, while the number remains the same in Class 09B. There is, in Class 09E, a shift from the concentration of scores in the range of 4 below to 6 to the range of 5 below to 7. This improvement shift cannot be seen in Class 09B where the score concentration is still in the 5-to-below-7 range. So, while most 09E-ers performed less well in the pretest, more of them wrote better in the posttest. As 09E-ers practiced to write less and read more during the course because they had to spend their time answering the questions for writing exploration, which were 
designed to be added in the experimental syllabus, the improvement of Class 09E could be considered as the result of more reading-to-write input they received, which was beneficial to their writing skill.

However, more students in Class 09B got the range of above 6 than those in Class 09E in the posttest. A closer look reveals that many more students scored from 6 and above in Class $09 \mathrm{~B}(43.4 \%=36.7 \%+6.7 \%)$ than in Class $09 \mathrm{E}$ (only $15.2 \%(9.1 \%+6.1 \%)$ ), almost one-third) in the pretest. The posttest result shows that Class $09 \mathrm{~B}$ got $50 \%(36.7 \%$ $+13.3 \%$ ) 6-and-above scores (increasing $6.6 \%$, from $43.4 \%=36.7 \%+6.7 \% 0$ to $50 \%$ ) while Class $09 \mathrm{E}$ got $24.3 \%$ $(18.2 \%+6.1 \%)$ (increasing $9.1 \%$, from $15.2 \%(9.1 \%+6.1 \%)$ to $24.3 \%)$. So while the percentage of increase in Class 09E is slightly higher than that in Class 09B, the percentage is still higher in Class 09B because from the beginning, it is much higher already.

It appears so lucid that the possibility of scoring worse in the posttest of writing skill is unlikely because after nine weeks of exposure to English; instead, because the writing performances reveal the real level of the students, the scores in the posttest mostly stay the same or increase. So, this might explain why many more students in Class 09B scored above 6 than in Class 09E, notwithstanding the amount of reading-to-write input 09E-ers received. Basically, the class with more students with higher level finally has more students in a higher range. And once again, it shows that the readlike-a-writer approach does not benefit students of higher level as much as it does with students of lower level.

\section{B. Responses from Questionnaires}

\section{Importance of writing}

When being asked whether or not writing is important (Question 1), all 58 students (100\%) and 8 teachers (100\%) give a positive answer, which shows that they can evaluate the significance of writing because this is one of the basic acquired language skills. Answers to Question 1 indicate the reasons why writing is important (see Table 2).

TABLE 2.

REASONS WHY WRITING IS SO IMPORTANT

\begin{tabular}{lllll}
\hline Question 1 & Students' responses & \multicolumn{2}{c}{ Teachers' responses } \\
\cline { 2 - 5 } & Total check & $\%$ & Total check & $\%$ \\
\hline Evaluate the students' English proficiency & 3 & $5.1 \%$ & 1 & $12.5 \%$ \\
\hline Be essential for the future careers & 5 & $8.5 \%$ & 3 & $37.5 \%$ \\
\hline Assist other English skills & 12 & $20.3 \%$ & 1 & $12.5 \%$ \\
\hline Improve knowledge application & 6 & $10.2 \%$ & 2 & $25 \%$ \\
\hline Reinforce grammar and enlarge vocabulary & 38 & $64.4 \%$ & 3 & $37.5 \%$ \\
\hline
\end{tabular}

Table 2 shows that most of the students $(64.4 \%)$ believe that writing can help them reinforce grammar and enlarge vocabulary and one-fifth of them $(20.3 \%)$ realize the relationship between writing and other language skills; to $37.5 \%$ of the teachers, be essential for future careers and reinforce grammar and increase vocabulary are two main reasons why writing skill is important.

\section{Students' frequency of writing practice}

Question 2 aims at finding out how often the student subjects practice writing outside class because practice is an indispensable factor in writing improving progress.

TABLE 3.

STUDENTS' FREQUENCY OF WRITING PRACTICE

\begin{tabular}{|c|c|c|c|c|}
\hline \multirow[t]{2}{*}{ Question 2} & \multicolumn{2}{|c|}{ Students' responses } & \multicolumn{2}{|c|}{ Teachers' responses } \\
\hline & Total check & $\%$ & Total check & $\%$ \\
\hline write as required & 53 & $89.8 \%$ & 7 & $87.5 \%$ \\
\hline a. twice a week & 2 & $3.4 \%$ & 0 & $0 \%$ \\
\hline b. four-five times a week & 1 & $1.7 \%$ & 0 & $0 \%$ \\
\hline c. write diary & 1 & $1.7 \%$ & 0 & $0 \%$ \\
\hline
\end{tabular}

Table 3 indicates that 53 students $(89.8 \%)$ practice writing as instructed. The number of the students who frequently practice writing is low (only $6.8 \%$ in which $1.7 \%$ write four to five times a week and $1.7 \%$ write everyday in the form of diary). The teachers share this opinion: $87.5 \%$ state that their students only practice as required and $12.5 \%$ think that their students never do it. The teachers' and students' responses to Question 2 infer that the students' awareness of the importance of self-practice in L2 learning writing is insufficient.

\section{Difficulty level of the essay writing}

Question 3 aims to confirm whether or not the essay writing is indeed a difficult task. 
TABLE 4.

DIFFICULTY LEVEL OF ESSAY WRITING

\begin{tabular}{lllll}
\hline \multirow{2}{*}{ Question 3 } & \multicolumn{3}{c}{ Students' responses } & \multicolumn{3}{l}{ Teachers' responses } \\
\cline { 2 - 5 } & Total check & $\%$ & Total check & $\%$ \\
\hline Difficult & 55 & 94.8 & 8 & 87.5 \\
\hline Not difficult & 3 & 6 & 0 & 12.5 \\
\hline
\end{tabular}

Table 4 proves that almost all the students $(93.2 \%)$ and the teachers $(87.5 \%)$ perceive the difficulty of essay writing. It can be obvious that it requires a painstaking effort and time to teach and learn how to compose a good essay

\section{Criteria for a well-formed essay}

Presented in Figure 1 and Figure 2 are the answers to question 4. Criteria are placed in their order of importance for measuring how good an essay is in which 1 is the most important criterion.

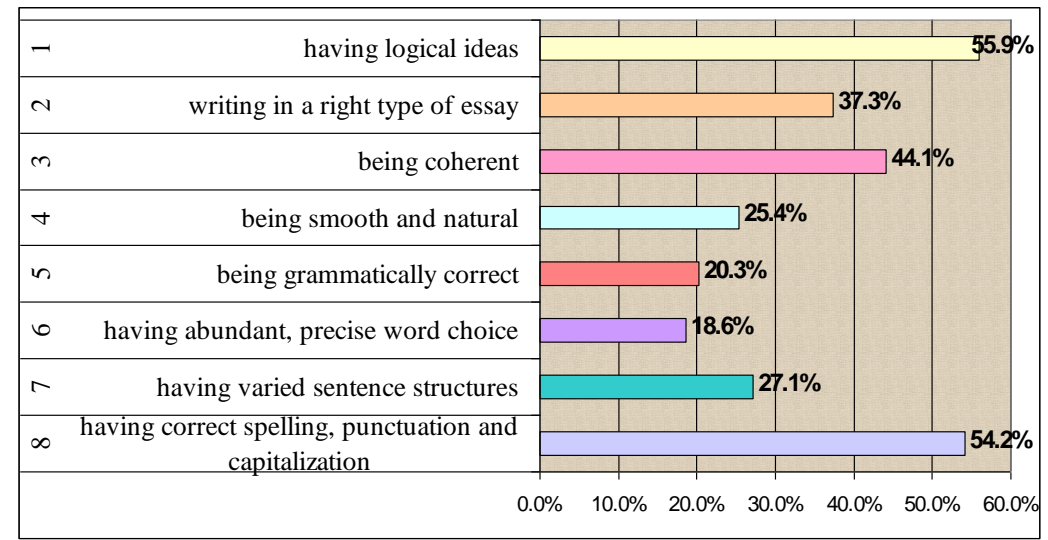

Figure 1. Students' responses to criteria for a well-formed essay

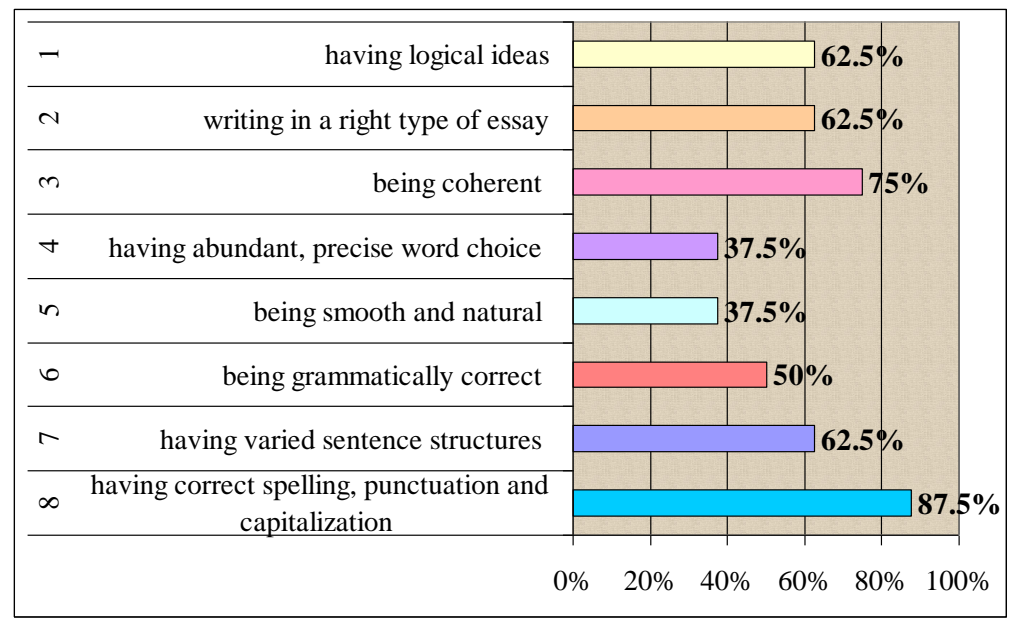

Figure 2. Teacher's responses criteria for a well-formed essay

Figure 1 and Figure 2 show that students and teachers share almost the same idea about the order of importance in which criteria for measuring how good an essay is occur:

+ "having logical ideas" is considered the most important criterion of a well-formed essay (55.9\% of the students and $62.5 \%$ of the teachers rank it the first).

+ "writing in a right type of essay" is ranked the second (37.3\% of the students and $62.5 \%$ of the teachers) because it is the common characteristic and it helps the reader follow the writer's ideas more easily.

+ "being coherent", "being grammatically correct" and "having varied sentence structures" are of relative significance as they attain the third, the fifth and the seventh position respectively.

+ "having correct spelling punctuation and capitalization" does not considerably affect the quality of the essay as much as $54.2 \%$ of the students and $87.5 \%$ of the teachers put it in the eighth position.

+ "being smooth and natural" and "having abundant and varied word choice" are valued differently by the teachers and the students: the students rank them the fourth position and the sixth position respectively while the teachers rank them the other way round.

Degree of difficulties encountered by the student writers 
The subjects' responses to Question 5 illustrated by Figure 3 and Figure 4 help to come up with difficulties encountered by the student writers. Figure 3 shows the degree of difficulties responded by the students in writing an essay in which 1 is the difficulty they encounter most.

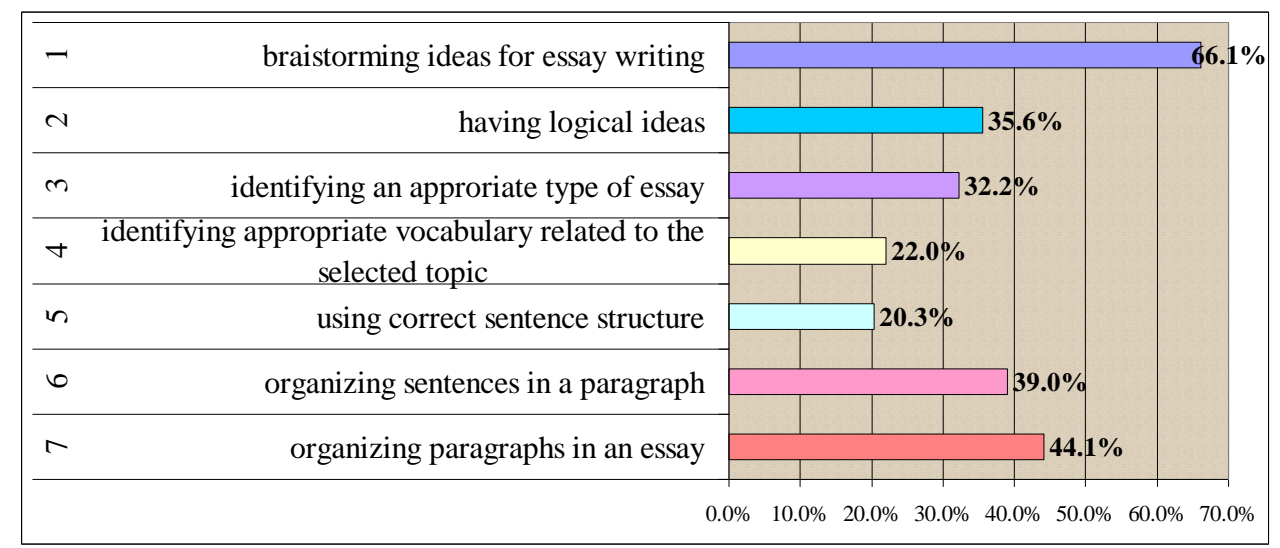

Figure 3. The degree of difficulties responded by the students in essay writing

Figure 4 shows the degree of difficulties responded by the teachers in writing an essay in which 1 is the difficulty they encounter most.

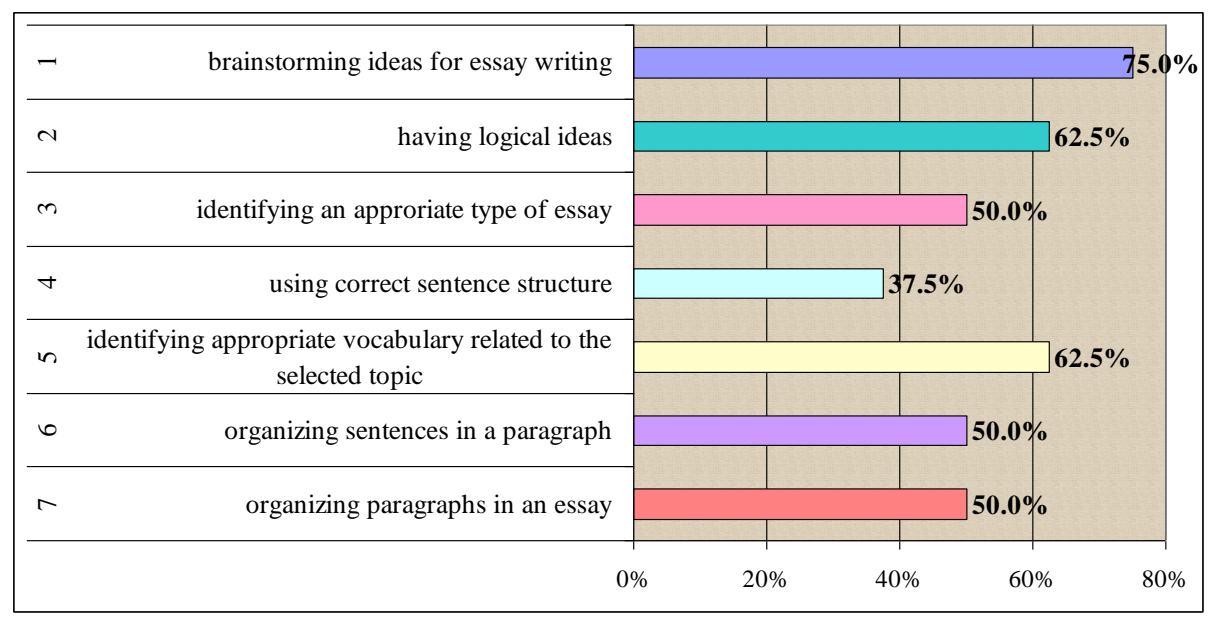

Figure 4 . The degree of difficulties responded by the teachers in essay writing

+ "Brainstorming ideas for essay writing" is considered the most difficult by $66.1 \%$ of the students and $75 \%$ of the teachers. Knowing what to say, which is usually done in pre-writing stage, is almost always the students' big problem. At this stage, the students are supposed to generate as well as determine ideas to convince their reader that their viewpoint is right.

+ "having logical ideas" is ranked the second obstacle of essay writing by $35.6 \%$ of the students and $62.5 \%$ of the teachers. It is not surprising as logical idea is the essay's prominent characteristic. In order to convince their reader, the students have to prove themselves as good writers by showing logical thinking.

+ "identifying the appropriate type of essay" is considered the third difficulty by $32.2 \%$ of the students and $50 \%$ of the teachers. This is reasonable because Vietnamese students are not familiar with writing in a direct way, they tend to write as much as possible what they can conceive without attending to the requirements for such types of essays.

+ "identifying appropriate vocabulary related to the given topic" and "using correct sentence structure" are evaluated variously by the teachers and the students: while the two are ranked the third and the fourth difficulty in writing the essay respectively by $22 \%$ and $20.3 \%$ of the students, the teachers rank the two the other round.

Reasons why the students are not good at writing

The subjects' responses to Question 6 in Figure 5 and Figure 6 aim to identify why the students are not good at writing. 


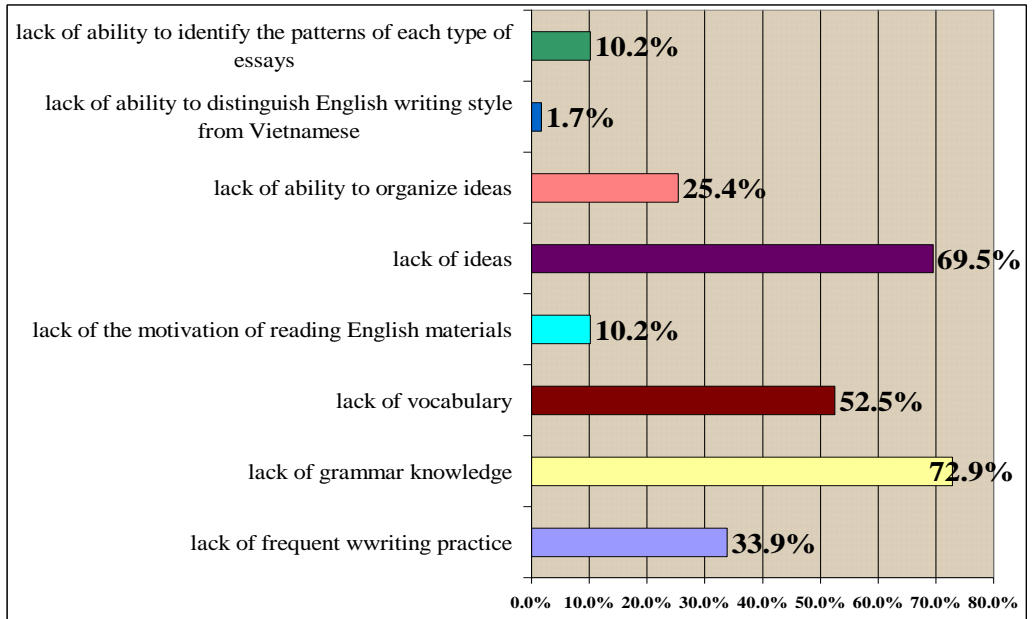

Figure 5. Reasons responded by students why students are not good at essay writing

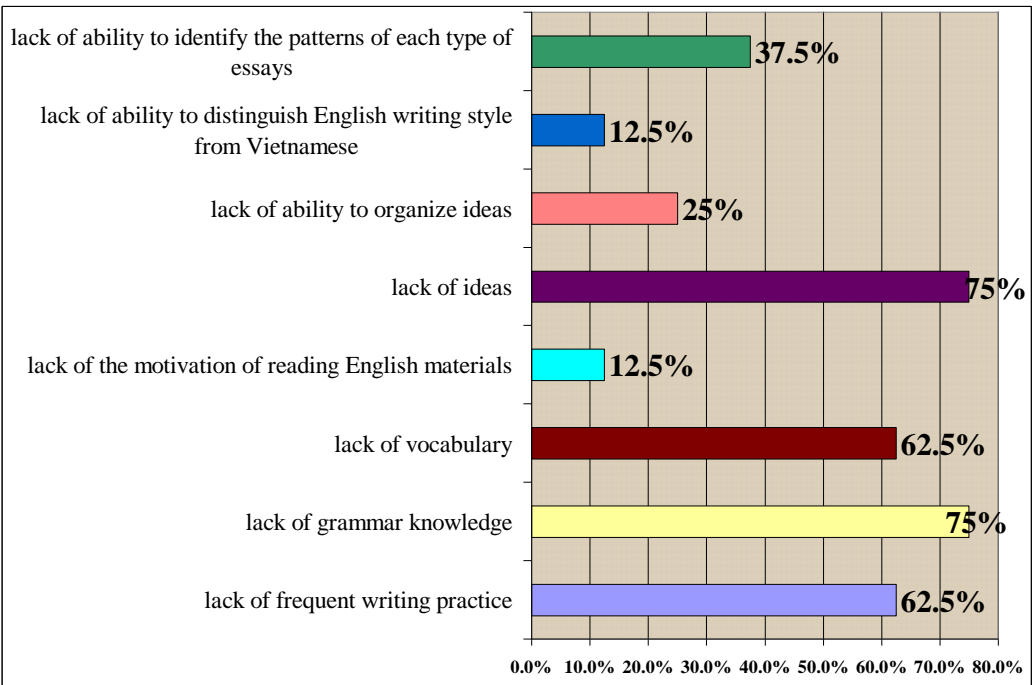

Figure 6. Reasons responded by teachers why students are not good at essay writing

Figure 5 and Figure 6 divulge that

+ "lack of grammar knowledge", "lack of ideas", "lack of frequent writing practice" and "lack of vocabulary" are considered by both the students and the teachers as the students' four most common reasons for their failure to gain competence in writing.

+ "lack of ability of identifying the patterns of each type of essays" is regarded as the fifth reason by $10.3 \%$ of the students and $37.5 \%$ of the teachers. The different percents infer that the students evaluate their grasp of each type of essay patterns higher than the teachers do.

\section{Suggestions to improve the teaching and learning of writing}

Suggestions to students

The subjects' responses to Question 7 as shown in Figure 7 and Figure 8 give light to what the students should do to improve their learning of writing.

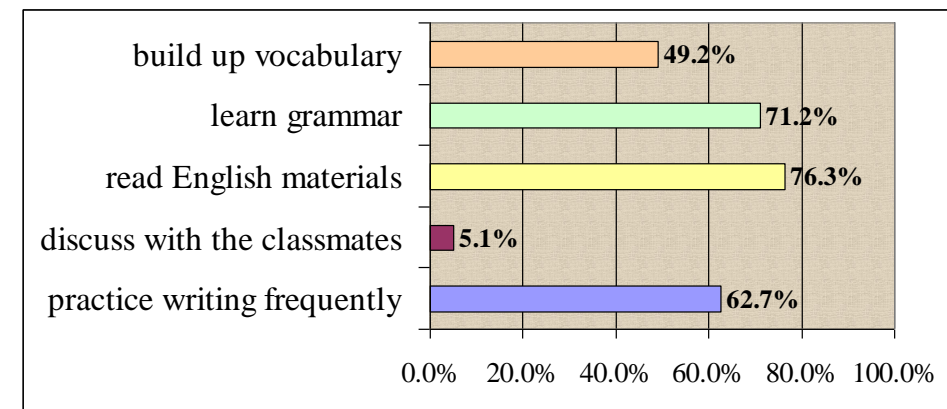

Figure 7. Students' suggestions to improve the students' learning writing 


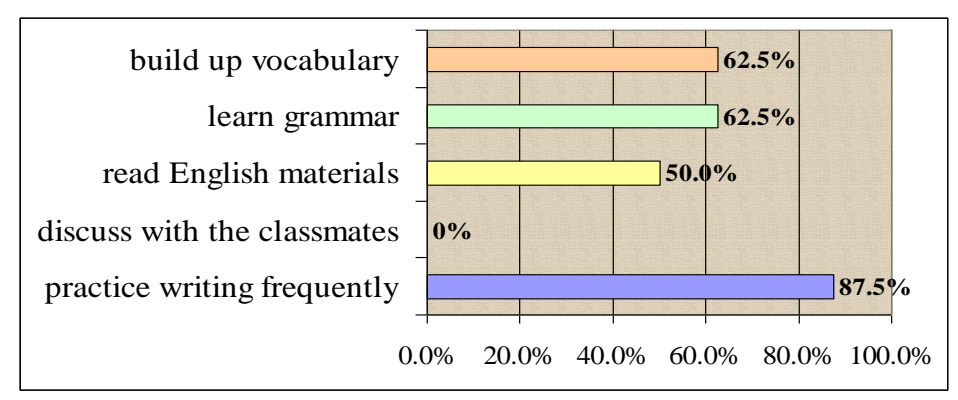

Figure 8. Teachers' suggestions to improve the students' learning writing

+ "Practice writing frequently" is proposed by $62.7 \%$ of the students and $87.5 \%$ of the teachers as a way to improve the students' writing. Suffering from their limited time for essay writing and lack of skills for self-study, not many of the student subjects are eager to practice writing by themselves out of class, especially without any guidance from their teacher; in contrast, the teacher subjects consider self-study essential at tertiary education.

+ "Learn grammar" is supported by $71.2 \%$ of the students and by $62.5 \%$ of the teachers as grammar incompetence is considered the most common reason affecting the students' writing.

+ "Build up vocabulary" is offered by $49.2 \%$ of the students and $62.5 \%$ of the teachers which are nearly the same as the percent of the students and the teachers who admit that lacking vocabulary prevents the students from gaining competence in writing.

+ "Read English materials" is recommended by $76.3 \%$ of the students and $50 \%$ of the teachers, which is contrary to small percents of the students and the teachers who acknowledge the lack of reading English materials for the students' failure to gain competence in writing. The difference may infer that both of the student and teacher subjects evaluate the usefulness of reading English in helping the students enlarge vocabulary and gather ideas for writing.

Suggestions to teachers

Figure 9 and Figure 10 propose what the teachers should do to improve their students' writing competence.

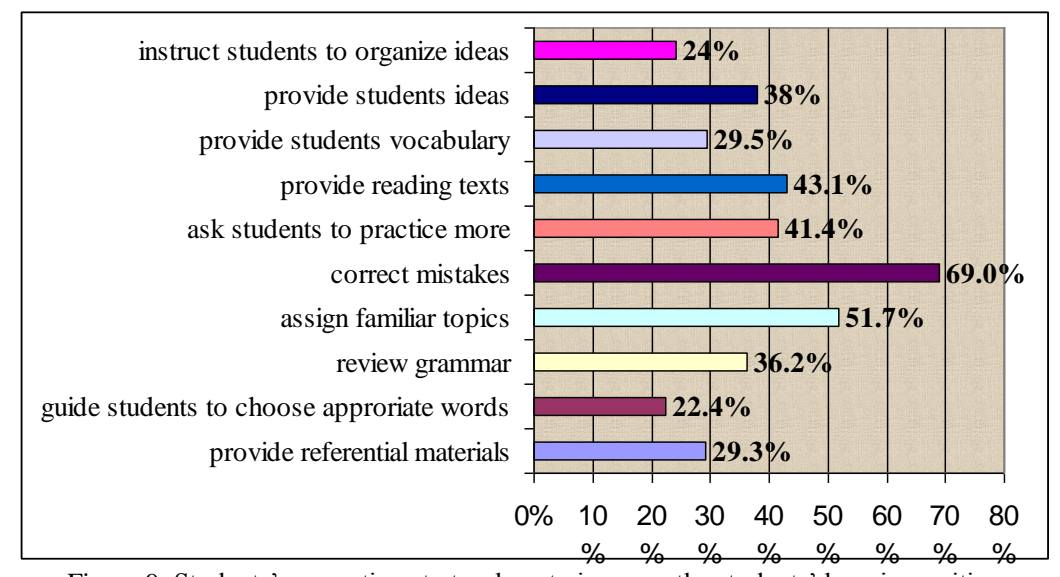

Figure 9. Students' suggestions to teachers to improve the students' learning writing

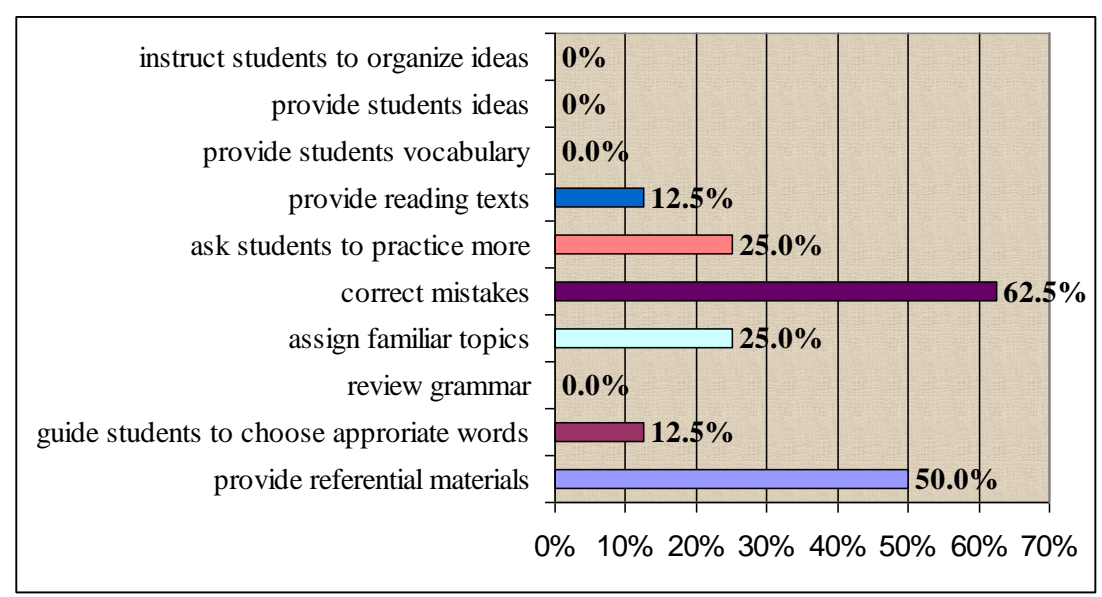

Figure 20. Teachers' suggestions to teachers to improve the students' learning writing 
+ "Correct mistakes" is proposed by $69 \%$ of the students and $62.5 \%$ of the teachers with more or less the same hope that the students can avoid making the mistakes.

+ "Provide referential materials" is suggested by $29.3 \%$ of the students and $50 \%$ of the teachers. The different percents show that the teachers evaluate the usefulness of reference materials more than the students do, especially in gathering ideas and enlarging vocabulary.

+ "Ask students to practice writing more" is recommended by $41.4 \%$ of the students and $25 \%$ of the teachers: on the one hand, the students suggest this to compensate for their lack of skills for self-study; on the other hand, the teachers do not have much time to correct their students' essays, hesitating to assign topics for homework.

+ "Provide reading texts" is offered by $43.1 \%$ of the students and $12.5 \%$ of the teachers. As finding and analyzing model essays are time-consuming, the teachers are reluctant to apply it in writing classes while the students find the usefulness of analyzing model essays to improve their writing.

+ "Provide students ideas" and "provide students vocabulary" related to the given topic are supported by $38 \%$ and $25.9 \%$ of the students respectively. However, none of the teachers propose them. On the one hand, the students assume that the teachers' providing ideas and vocabulary related to the given topic can facilitate the students' writing. On the other hand, the teachers consider that this may leave the students with a false impression that their lack of ideas and vocabulary does not affect their writing essays as they really do in reality, especially when the students take examination.

+ "Review grammar" is suggested by $36.2 \%$ of the students. However, none of the teachers propose it as for the fourth-year students reviewing grammar is their own duty.

\section{CONCLUDing REMARKS}

The conclusion drawn from the questionnaire analysis of the teachers' and the students' responses towards the problems facing the fourth-year students of Ho Chi Minh City University of Finance-Marketing in writing essays was rather the same implications as the mutual understanding between the teachers and the students which helps the teachers design their lesson plans suitable for the students' needs. The difference between teachers and student subjects in proposing suggestions to improve the students' writing demonstrates the teachers' enthusiasm insufficiency and the students' passive role in the teaching and learning of writing - a time-and-effort consuming work.

\section{REFERENCES}

[1] Battle, M.V. (1986). Evaluated Quantitative Research for Relating Reading and Writing in Beginning College English. MidSouth Educational Research, ERIC ED 285171.

[2] Brown, H. (1987). Principles of language learning and teaching. Englewood Cliffs, NJ: Prentice Hall

[3] Byrne, D. (1988). Teaching Writing Skills. London: Longman.

[4] Flower, L., and Hayers, J.R. (1980). The Cognitive of Discovery Defining a Rhetorical Problem. College Composition and Communication, 31 (1): 21-32.

[5] Hegde, T. (1998). Writing. Oxford: Oxford University Press.

[6] Kucer, S. (1985). The making of meaning: Reading and Writing as Parallel Processes. University of Southern California.

[7] Murcia, M.C. and Olshtain, E. (2000). Discourse and Context in Language Teaching: A Guide for Language Teachers. Cambridge: Cambridge University Press.

[8] Nunan, D. (1999). Second Language Teaching and Learning. USA: Heinle \& Henle Publishers.

[9] Peha, S. (2003). What is good writing? Retrieved on 20 May 2011 from the website Teaching That Makes Sense at http://www.ttms.org/.

[10] Silva, T. (1990). Second language composition instruction: Developments, issues, and directions in ESL. In B. Kroll (ed.), Second Language Writing: Research Insights for the Classroom. Cambridge: Cambridge University Press.

[11] Smalley, R.L. and Ruetten, M.K. (1986). Refining Composition Skills, Rhetoric and Grammar for ESL students. New York: Macmillan Publishing Company.

[12] Smith, F. (1983). Reading like a writer. In J.M. Jensen (Ed.), Composing and Comprehending. Urbana. ERIC Clearinghouse on Reading and Communication Skills.

[13] Spandel, V. (1996). Seeing With New Eyes: A Guidebook on Teaching and Assessing Beginning Writers. Portland, OR: Northwest Regional Educational Laboratory.

[14] Tribble, C. (1996). Writing. Oxford: Oxford University Press.

Luu Trong Tuan is currently an EFL teacher at Ho Chi Minh City University for Natural Resources and Environment. He received his M.TESOL from Victoria University, Australia in 2004. Besides his focus on TESOL, his recent publications such as Language Transfer is Cultural Transfer between Communities, Social Sciences Review, No. 11, 2004, pp. 60-63; and Principles for Scientific Translation, Social Sciences Review, No. 8, 2004, pp. 63-67; and Building Vietnamese Medical Terminology via Language Contact, Australian Journal of Linguistics, Vol. 29, No. 3, September 2009, pp. 315-336 show his interest in language contact and translation areas. 